\title{
Hamster Mammary Carcinoma
}

National Cancer Institute

\section{Source}

National Cancer Institute. Hamster Mammary Carcinoma. NCI Thesaurus. Code C135723.

Carcinoma of the mammary gland that occurs in a hamster. 